\title{
Warming Water in Arctic Terrestrial Rivers under Climate Change ${ }^{\mathscr{D}}$
}

\author{
HOTAEK PARK \\ Institute of Arctic Climate and Environment Research, JAMSTEC, Yokosuka, and Institute for Space-Earth \\ Environmental Research, Nagoya University, Nagoya, Japan \\ YASUHIRO YOSHIKAWA \\ Department of Civil and Environmental Engineering, Kitami Institute of Technology, Kitami, Hokkaido, Japan \\ DAQING YANG \\ National Hydrology Research Centre, Environment Canada, Saskatoon, Saskatchewan, Canada \\ KAZUHIRO OSHIMA \\ Institute of Arctic Climate and Environment Research, JAMSTEC, Yokosuka, Japan
}

(Manuscript received 3 November 2016, in final form 24 April 2017)

\begin{abstract}
Recent years have seen an obvious warming trend in the Arctic. Streamflow and water temperature $T_{w}$ are important parameters representing the changes of Arctic rivers under climate change. However, few quantitative assessments of changes in river $T_{w}$ have been conducted at the pan-Arctic scale. To carry out such an assessment, this study used a modeling framework combining a land process model [the coupled hydrological and biogeochemical model (CHANGE)] with models of river discharge $Q$, ice cover, and $T_{w}$ dynamics. The $T_{w}$ model was improved by incorporating heat exchange at the air-water interface and heat advection from upstream through the channel network. The model was applied to pan-Arctic terrestrial rivers flowing into the Arctic Ocean over the period 1979-2013 and quantitatively assessed trends of $T_{w}$ at regional and pan-Arctic scales. The simulated $T_{w}$ values were consistent with observations at the mouths of major pan-Arctic rivers. The model simulations indicated a warming trend of $T_{w}$ by $0.16^{\circ} \mathrm{C}$ decade ${ }^{-1}$ at the outlets of the pan-Arctic rivers, including widespread spatial warming consistent with increased air temperature $T_{a}$. The strong impact of $T_{a}$ on $T_{w}$ was verified by model sensitivity analysis based on various scenarios involving changes in the $T_{a}$ and $Q$ forcings. Finally, this study demonstrated the warming of $T_{w}$ in Arctic rivers induced by $T_{a}$ warming, suggesting the potential for warming $T_{w}$ of Arctic rivers under future climate change scenarios.
\end{abstract}

\section{Introduction}

River water temperature $T_{w}$ is one of the most important parameters affecting freshwater biogeochemistry and the physical properties of surface water in rivers and lakes. The heating and cooling processes of $T_{w}$ in rivers are greatly influenced by meteorological and hydrological conditions over a wide range of spatial and temporal scales. The Arctic rivers are mostly ice covered during

Supplemental information related to this paper is available at the Journals Online website: http://dx.doi.org/10.1175/ JHM-D-16-0260.s1.

Corresponding author: Hotaek Park, park@jamstec.go.jp winter, with relatively stable $T_{w}$ values, and $T_{w}$ varies significantly during the ice-free season when air temperatures $T_{a}$ are above $0^{\circ} \mathrm{C}$. A higher $T_{a}$ enhances the net exchange of thermal energy across the air-water interface, resulting in a higher $T_{w}$. Previous studies have addressed the high correlation between $T_{a}$ and $T_{w}$ (Stefan and Preud'homme 1993; Webb et al. 2008). Significant Arctic warming has occurred over the past several decades (Bekryaev et al. 2010), and observations have indicated warming $T_{w}$ at the mouths of the major Arctic rivers, along with the warming trend in $T_{a}$ (Liu et al. 2005; Lammers et al. 2007; Yang et al. 2014).

Variations in river discharge $Q$ are closely correlated to changes in heat capacity and travel time, affecting $T_{w}$ (van Vliet et al. 2012). Observational studies have 
documented a long-term increase in $Q$ of the pan-Arctic rivers (Peterson et al. 2002; Holmes et al. 2015). In addition to this increase, there has been a consistent shift toward earlier peak discharge in the spring (Shiklomanov et al. 2007; Holmes et al. 2015; Yang et al. 2007). Moreover, changes were identified in river-ice phenology; river ice melts earlier in spring and freezes later in autumn (Park et al. 2016). The longer ice-free period contributes to the warming of $T_{w}$. Warmer $T_{w}$ combined with increased $Q$ likely results in a higher lateral input of heat to the coastal domain of the shallow shelf area. Analysis of observation records near the outlets of the major Arctic rivers showed increases in river heat flux to the Arctic Ocean (Liu et al. 2005; Lammers et al. 2007; Yang et al. 2014; Whitefield et al. 2015).

Most previous studies of the $T_{w}$ of the Arctic rivers were restricted to larger major river basins because of limited observational records. Larger rivers certainly make higher quantitative contributions than small rivers; for example, $Q$ from the four major rivers (e.g., $\mathrm{Ob}$, Yenisei, Lena, and Mackenzie) in the Arctic accounted for about $70 \%$ of total gauged discharge (Serreze et al. 2006). Although their quantitative contributions are lower, the freshwater from numerous smaller rivers across the pan-Arctic mainland has the potential to disrupt deep convection and thereby inhibit global thermohaline circulation, wherein ocean currents redistribute heat and help moderate the climate (Alkire et al. 2015; Prowse et al. 2015). These implications reinforce the need for quantitative assessments of $T_{w}$ in all Arctic terrestrial rivers experiencing the effects of climate change.

Numerical modeling is a useful tool to quantitatively assess the status and changes of river $T_{w}$ from the basin to global scale. Hydrological and process-based water temperature models have been developed, but few studies have simulated both $Q$ and $T_{w}$ of pan-Arctic rivers over long time periods (van Beek et al. 2012; van Vliet et al. 2012; Park et al. 2016). These studies have increased the role of models in studying impacts of climate change on river hydrology and its impacts on polar oceans. In the Arctic, the last decade has been characterized by an anomalously high warming rate of $T_{a}$ (Overland et al. 2015) and increasing $Q$ (Holmes et al. 2015). These climatic and hydrologic changes are directly associated with heat exchange at the river surface, and heat capacity and travel time of river water, which together alter the river's $T_{w}$. However, very few studies have provided quantitative assessments of changes in $T_{w}$ in Arctic rivers in recent years, addressing the potential changes caused by a warming climate.

Recently, Park et al. (2016) coupled an ice process algorithm into a hydrological process-based river $T_{w}$

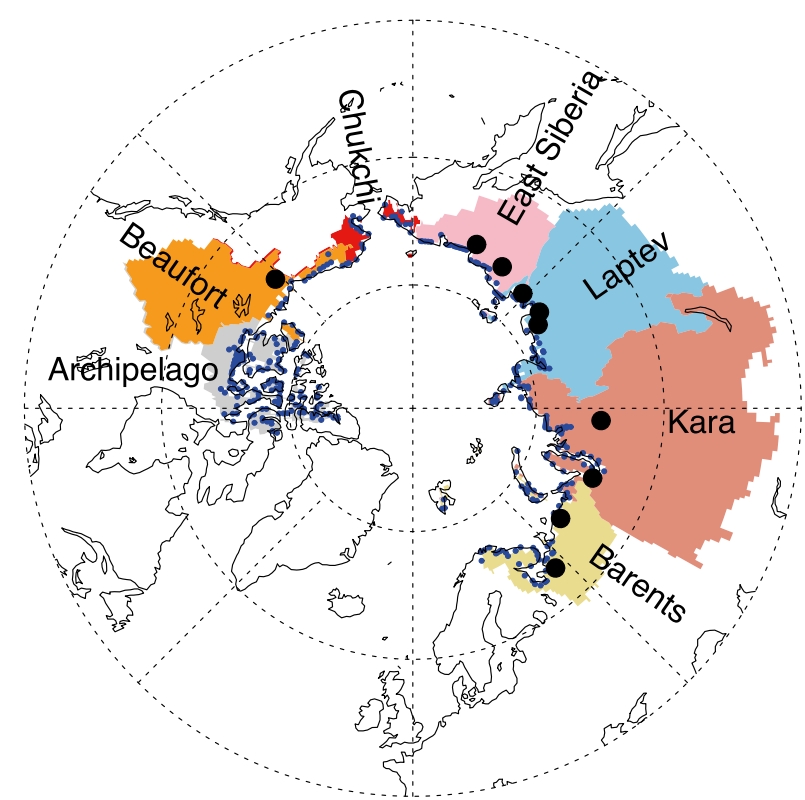

FIG. 1. The Arctic river basins used for model evaluations in this study, organized by sea boundaries. Blue dots represent river mouth locations for all river basins within the river system. Black dots represent outlet locations of the major rivers, where observations were made for assessing the accuracy of modeled river temperature.

model. The model captured the seasonal patterns in $T_{w}$ observations well at the mouths of the large Arctic rivers, although the simulations were cold biased relative to in situ observations (Park et al. 2016). Parameter $T_{w}$ is most sensitive to both heat exchange at the airwater interface and heat advection from upstream along the drainage network (van Vliet et al. 2012). Based on this knowledge, heat flux processes have been incorporated into the model framework (Park et al. 2016). The new model simulates $T_{w}$ in pan-Arctic rivers at a daily time step with $0.5^{\circ}$ spatial resolution on a regular grid.

The main objective of this study was to assess the spatiotemporal variability and trends in $T_{w}$ in panArctic rivers (Fig. 1) during the period of 1979-2013, based on simulations by the modified model. A model sensitivity study was conducted to delineate the factors affecting $T_{w}$, which were diagnosed by experiments that incorporated several different climatic and hydrologic forcing scenarios into the model. The model results were compared with observational data collected near the outlets of the major Arctic rivers (Fig. 1).

\section{Model description}

\section{a. Land surface process model and routing model}

The coupled hydrological and biogeochemical model (CHANGE; Park et al. 2011) is a grid-based 
macroscale land surface model that calculates heat, water, and carbon fluxes in the atmosphere-land system. The model includes variability of elevation, soil, snow, and vegetation across the grid. In the soil column down to $50.5 \mathrm{~m}$ depth, the model estimates the heat and hydraulic conduction with explicit treatment of soil freezing and thawing phase transitions. Water flowing into the soil surface is split into surface runoff and infiltration to the deep soil layers. The vertical fluxes of water between soil layers are solved using Darcy's law, where excess soil water is routed to deeper soil layers. The excess water at either the upper boundary of permafrost or the bottom soil layer is added to subsurface runoff.

The river routing scheme Total Runoff Integrating Pathways, version 2 (TRIP2; Ngo-Duc et al. 2007), was used to simulate river flow through the stream channel. TRIP2 is a storage-based, distributed river routing model with subgrid parameters representing a realistic travel time without calibration. It calculates river water storage, river discharge, water depth, and channel width. Water storage is the only prognostic variable, with the other variables estimated based on water storage. Surface and subsurface runoff values calculated by CHANGE are stored in individual storage reservoirs where water is routed along a prescribed channel network to the basin outlet. The contribution of subsurface runoff to $Q$ is represented by a linear groundwater delay parameter, depending on the soil type in the grid cell. Ice formation and its effects on heat storage and river hydraulics are also included. The model performance for reproducing the seasonal and interannual variability of $Q$ was validated with observational $Q$ data from the major Arctic rivers (Park et al. 2016).

\section{b. Stream temperature model}

For a given stream segment within a drainage network, $T_{w}$ is determined based on the inflow of upstream heat into the stream segment, the dominant heat exchange at the air-water interface, and the inflow of heat and water from tributaries. Advection dominates heat transport in larger natural river systems, and thus we assumed that lateral heat transport is driven by advection only, which is reasonable for most large rivers with high flow velocities (Sinokrot and Stefan 1993). In large rivers, the higher discharge results in strong lateral and vertical mixing of water, reducing the impact of processes such as heat exchange at the streambed-water interface and groundwater advection on $T_{w}$ (Liu et al. 2005; Caissie 2006; van Vliet et al. 2012). Very few observations of streambed heat flux are available, which limits model development and improvement. It was therefore assumed that the streambed heat flux is negligible in the model simulations. The surface water energy balance is described as

$$
\rho C_{p} \frac{\partial\left(T_{w} A\right)}{\partial t}=\Phi w_{x}+\rho C_{p} Q_{\mathrm{trb}} \frac{\partial T_{\mathrm{trb}}}{\partial x},
$$

where $\rho$ is the density of water $\left(\mathrm{kg} \mathrm{m}^{-3}\right), C_{p}$ is the specific heat capacity of water $\left(\mathrm{J} \mathrm{kg}^{-1}{ }^{\circ} \mathrm{C}^{-1}\right), A$ is the crosssectional area of the river at distance $x\left(\mathrm{~m}^{2}\right), \Phi$ is the heat flux at the air-water interface $\left(\mathrm{J} \mathrm{m}^{-2} \mathrm{~s}^{-1}\right), w_{x}$ is stream width at distance $x(\mathrm{~m}), Q_{\mathrm{trb}}$ is the discharge from tributaries or upstream $\left(\mathrm{m}^{3} \mathrm{~s}^{-1}\right), \Delta T_{\text {trb }}$ is the difference in temperature from tributaries or upstream, and $t$ is time (s). Equation (1) is solved with a predictor-corrector approach using Euler's method, assuming constant density flowing through a rectangular channel with perfect vertical mixing and using a daily time step on a regular grid with $0.5^{\circ}$ spatial resolution (van Beek et al. 2012; van Vliet et al. 2012). The predictor-corrector method provides stability for solving the differential equation without the plague of numerical dispersion.

The net heat flux at the air-water interface is calculated as the summation of the different heat flux components (Wunderlich and Gras 1967) as

$$
\Phi=\left(\Phi_{s}-\Phi_{\mathrm{rs}}\right)+\left(\Phi_{a}-\Phi_{\mathrm{ar}}\right)+\Phi_{\text {evap }}+\Phi_{\text {cond }}+\Phi_{\text {back }},
$$

where $\Phi_{s}$ is shortwave solar radiation $\left(\mathrm{J} \mathrm{m}^{-2} \mathrm{~s}^{-1}\right), \Phi_{\mathrm{rs}}$ is reflected shortwave radiation $\left(\mathrm{J} \mathrm{m}^{-2} \mathrm{~s}^{-1}\right), \Phi_{a}$ is longwave atmospheric radiation $\left(\mathrm{J} \mathrm{m}^{-2} \mathrm{~s}^{-1}\right), \Phi_{\mathrm{ar}}$ is reflected atmospheric radiation $\left(\mathrm{J} \mathrm{m}^{-2} \mathrm{~s}^{-1}\right), \Phi_{\text {evap }}$ is evaporative heat flux $\left(\mathrm{J} \mathrm{m}^{-2} \mathrm{~s}^{-1}\right), \Phi_{\text {cond }}$ is the conductive or convective heat flux $\left(\mathrm{J} \mathrm{m}^{-2} \mathrm{~s}^{-1}\right)$, and $\Phi_{\text {back }}$ is blackbody radiation from the water surface $\left(\mathrm{J} \mathrm{m}^{-2} \mathrm{~s}^{-1}\right)$. To calculate $\Phi_{\mathrm{rs}}$, we assumed that the albedo of open water is 0.12 , and that of ice cover is 0.8 . This treatment was possible because the model included the snow effect on the change in ice thickness (Park et al. 2016).

The initial conditions of $T_{w}$ in all grid cells are required for model simulation. The initial $T_{w}$ was set to $0^{\circ} \mathrm{C}$ in all grid cells, and then allowed to reach a stable condition during the spinup calculation of two consecutive years using data from 1979. The upstream boundary conditions (i.e., headwater $T_{w}$ ) are also required for simulation. The headwater temperature is calculated at every time step by removing the second term from the right-hand side of Eq. (1), which can be used to simulate $T_{w}$ at a specific location within a river network (Caissie et al. 2007).

\section{Methodology and data}

The model was applied to all river basins in the Arctic (Fig. 1) for the period of 1979-2013 to assess changes in 
$T_{w}$ at a wide range of temporal and spatial scales. A globally gridded climatic forcing dataset, WATCH Forcing Data Methodology Applied to ERA-Interim Data (WFDEI), which was developed by the EU Sixth Framework Programme Water and Global Change (WATCH) project (Weedon et al. 2014), was used for the model. Using the WFDEI dataset with a 3-h time step, CHANGE simulated land surface processes with a static land-cover classification for the period of 19792013. Vegetation phenology was simulated based on estimated carbon and nitrogen fluxes. Vertical soil profiles including sand, clay, and silt were used for the estimation of soil thermal and hydraulic properties, in combination with simulated soil organic matter at each time step. The output data from CHANGE (i.e., daily surface and subsurface runoff) were then provided to the offline routing model to simulate channel flows, depth, and width on a stream reach basis. In addition to the channel information, daily meteorological data (temperature, radiation, precipitation, relative humidity, vapor pressure, and wind speed) were used to force the water temperature model in individual grid cells. The models also used the channel network with $0.5^{\circ}$ resolution (Oki and Sud 1998) for the simulations of $Q$ and $T_{w}$.

Simulated $T_{w}$ depends heavily on the quality of meteorological data. The Arctic region contains a low density of meteorological stations, which increases uncertainty in the simulations. Parameter $T_{w}$ is highly correlated to $T_{a}$ (Webb et al. 2008; Yang and Peterson 2017), and therefore, we designed model sensitivity experiments to diagnose how changes in $T_{a}$ affect the modeled $T_{w}$. The sensitivity experiments were based on 12 scenarios, including a control run that used the original forcing dataset. To assess the influence of $T_{a}$ changes on $T_{w}, T_{a}$ was adjusted by $\pm 2^{\circ} \mathrm{C}$ on an annual basis from the baseline forcing data. We also assessed the uncertainties in simulated $T_{w}$ associated with changes in $Q( \pm 25 \%$ and $\pm 50 \%)$. The change in $Q$ of $\pm 25 \%$ was combined with $\pm 2{ }^{\circ} \mathrm{C}$ in $T_{a}$.

Daily $T_{w}$ records measured at the mouths of the major Arctic rivers (Fig. 1) were used to validate the model simulations. Lammers et al. (2007) compiled a Eurasian river $T_{w}$ dataset, with observations from 20 stations extending from the mid-1930s to the early 2000s. The available records from 1979 onward were used to assess simulated $T_{w}$ dynamics. Yang et al. (2014) archived an observational $T_{w}$ dataset for the Mackenzie River, including observations made at various locations and times by Canadian government agencies. We used $T_{w}$ data observed at the Arctic Red River station of the Mackenzie basin from 1979 to 2009 for this study.

The performance of the model was assessed by comparing daily $T_{w}$ simulations against observation records using the statistical parameters root-mean-square error (RMSE), mean bias (BIAS), the Nash coefficient (NASH), and the Pearson correlation coefficient $r$. The correlation coefficient was calculated to quantify the linear relationship between simulated and observed values. Trend analysis and significance testing were carried out using the nonparametric Mann-Kendall test.

\section{Results}

\section{a. Model performance for daily water temperature}

The water temperature observations from Russian rivers were 10-day averages from daily data (Lammers et al. 2007), as was the simulated $T_{w}$. Figure 2 compares daily and seasonal variations in simulated $T_{w}$ and observations at the mouths of the five major Arctic rivers. For clarity, only 10-yr time series for the data-rich period of 1985-94 are shown. The model results indicate a good performance, realistically simulating both the seasonal variation in the rising and falling limbs of $T_{w}$ at most stations and the $T_{w}$ variability among years (Fig. 2). In particular, the modeling framework that included riverice processes captured the timing of the start $\left(T_{w} \geq 0^{\circ} \mathrm{C}\right)$ and end $\left(T_{w}<0^{\circ} \mathrm{C}\right)$ of the river-ice cover quite well. However, the model slightly overestimated early spring $T_{w}$ in most river basins. In nature, broken river ice gradually melts in spring as it flows down the river. This increases both albedo and latent heat, causing $T_{w}$ to rise later in the spring than in rivers without an ice pack. The model assumed that the broken ice immediately melts; this assumption was likely associated with the overestimation.

The inclusion of both surface energy exchanges and heat advection from upstream or tributaries through the river network resulted in a significant improvement in model simulation of the timing and magnitude of the peak summer temperature (Fig. 2b). The model raised summer temperature by about $1^{\circ}-6^{\circ} \mathrm{C}$ relative to previous results that did not consider the impacts of heat exchange and advection (Park et al. 2016). A noticeable rise in temperature was also found along the falling limb of $T_{w}$ at all stations (Fig. 2b). Comprehensive statistics regarding model performance at all stations chosen for comparison are summarized in Table 1. The improvement in model performance was reflected by the statistical values compared to the previous model results for all stations (Table 1); RMSE and BIAS for all stations were smaller, while the correlation coefficients were larger than the previous model values. For example, the absolute BIAS for all stations was less than $1^{\circ} \mathrm{C}$, which was comparable to the absolute values of $\sim 0.2^{\circ}-2.4^{\circ} \mathrm{C}$ at key stations for three Siberian river basins documented by van Vliet et al. (2012) (Table 1). Furthermore, the 
(a)

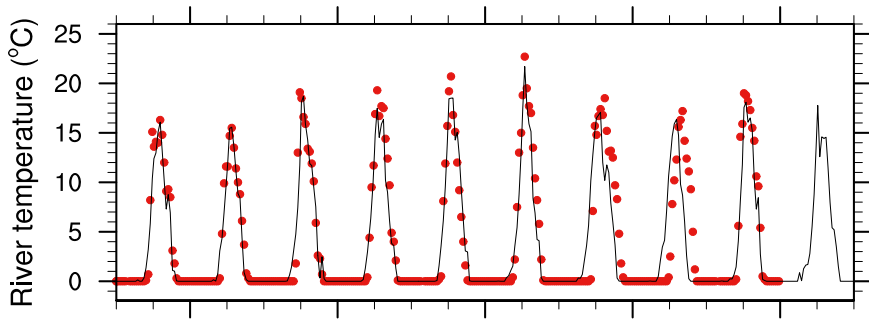

Yenisey (lgarka)

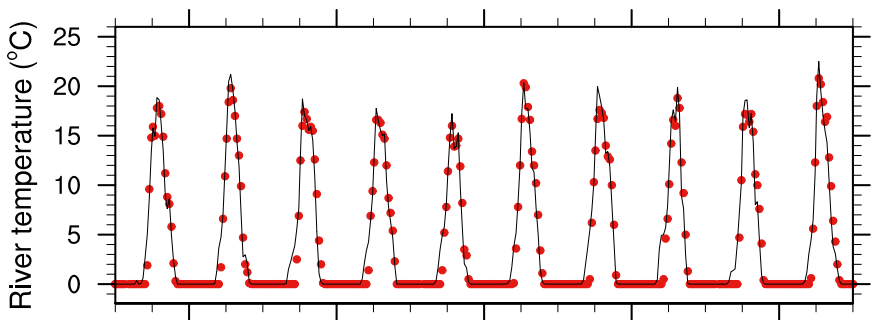

Lena (Kusur)

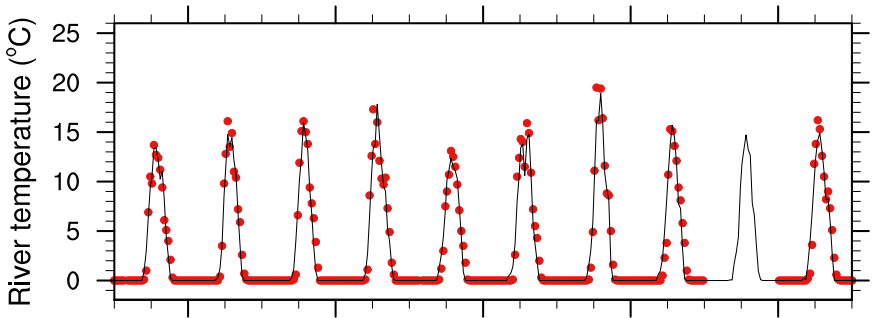

(b)
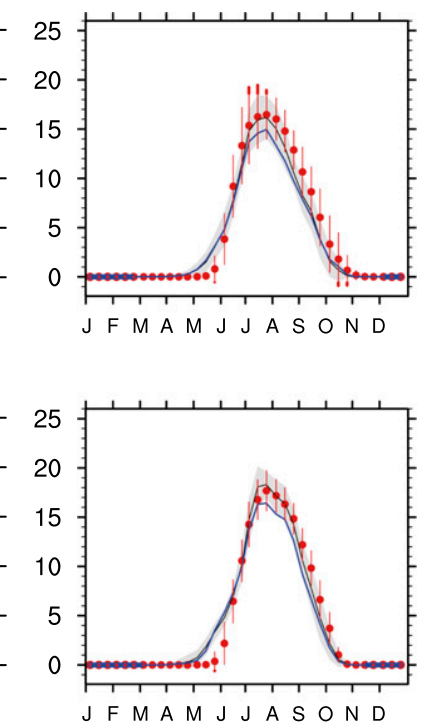

JFMAMJJASOND

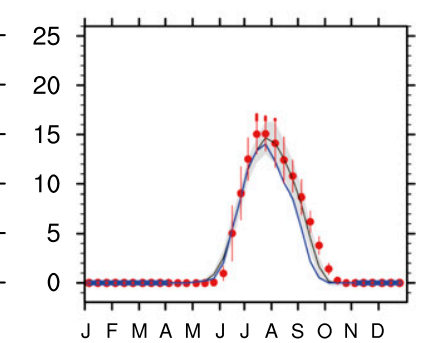

Kolyma (Kolymskoye)

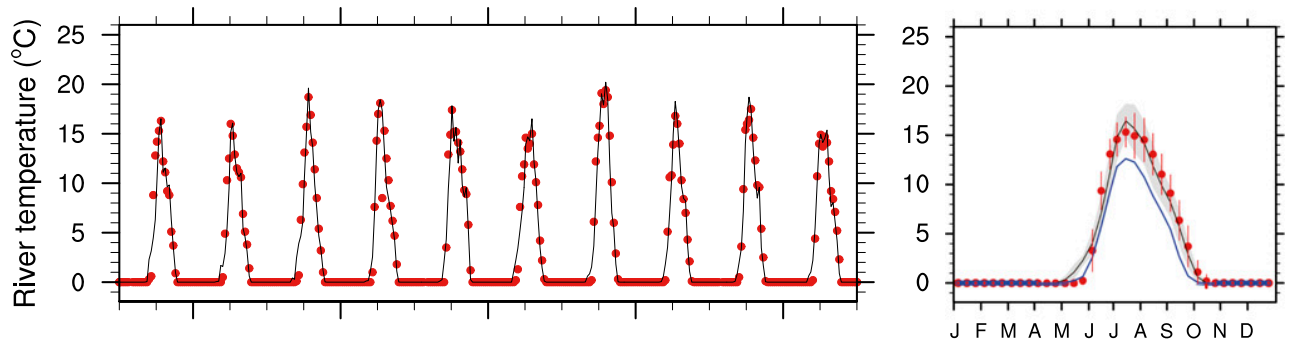

Mackenzie (Arctic Red)
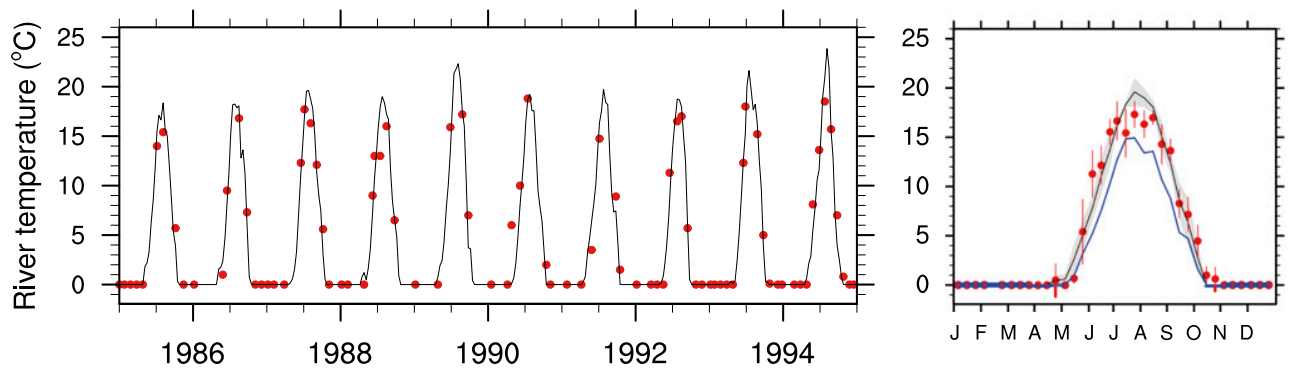

FIG. 2. Comparison of modeled river water temperature (lines) against observations (dots) recorded at the outlet stations of the major Arctic river basins over (a) interannual and (b) seasonal time scales. The simulation results displayed here were averaged over 10 days, corresponding to the observational records. In (b), the shading and vertical lines represent one std dev for the model simulation and observation, respectively, for the period that observations were available. The results (blue lines) simulated by the old modeling framework (Park et al. 2016) are also displayed for comparison. 
TABLE 1. Summary of statistical measures, including RMSE, BIAS, NASH, and $r$, comparing the observations and simulations of water temperature at the individual river mouths. The trend $\left({ }^{\circ} \mathrm{C} \mathrm{r}^{-1}\right)$ was calculated using the nonparametric Mann-Kendall test based on the simulated values for the 1979-2013 simulation period. Vliet represents values documented by van Vliet et al. (2012), and Lam represents trends provided by Lammers et al. (2007). Variable $p$ represents the probability for the trend calculated by this study.

\begin{tabular}{|c|c|c|c|c|c|c|c|c|c|c|c|c|c|c|c|}
\hline \multirow[b]{2}{*}{ River } & \multirow[b]{2}{*}{ Station name } & \multicolumn{3}{|c|}{ RMSE } & \multicolumn{3}{|c|}{ BIAS } & \multicolumn{2}{|c|}{ NASH } & \multicolumn{3}{|c|}{$r$} & \multicolumn{2}{|c|}{ Trend } & \multirow[b]{2}{*}{$p$} \\
\hline & & New & Old & Vliet & New & Old & Vliet & New & Old & New & Old & Vliet & New & Lam & \\
\hline Severnaya Dvina & Ust Pinega & 2.51 & 2.85 & & 0.62 & -0.63 & & 0.89 & 0.86 & 0.95 & 0.94 & & 0.020 & 0.007 & 0.017 \\
\hline Pechora & Oksino & 1.62 & 1.64 & & 0.01 & -0.90 & & 0.94 & 0.94 & 0.97 & 0.99 & & 0.012 & 0.010 & 0.222 \\
\hline $\mathrm{Ob}$ & Salekhard & 2.52 & 2.82 & 4.1 & -0.62 & -1.00 & -2.4 & 0.86 & 0.83 & 0.93 & 0.93 & 0.76 & 0.012 & -0.001 & 0.111 \\
\hline Yenisey & Igarka & 1.68 & 2.17 & 2.8 & 0.14 & -0.50 & -0.2 & 0.94 & 0.90 & 0.97 & 0.96 & 0.95 & 0.010 & -0.011 & 0.164 \\
\hline Olenek & Buurs mouth & 1.78 & 1.89 & 3.2 & -0.16 & -0.67 & -1.2 & 0.91 & 0.89 & 0.95 & 0.95 & 0.87 & 0.014 & -0.024 & 0.031 \\
\hline Lena & Kusur & 1.41 & 2.09 & & -0.36 & -1.20 & & 0.94 & 0.87 & 0.97 & 0.96 & & 0.014 & 0.002 & 0.025 \\
\hline Yana & Ubileinaya & 1.64 & 1.75 & & 0.37 & -0.66 & & 0.92 & 0.91 & 0.96 & 0.96 & & 0.021 & 0.009 & 0.008 \\
\hline Indigirka & Vorontsovo & 1.69 & 3.53 & & 0.21 & -2.29 & & 0.92 & 0.62 & 0.96 & 0.90 & & 0.015 & -0.002 & 0.041 \\
\hline Kolyma & Kolymskoye & 1.87 & 3.29 & & -0.21 & -2.42 & & 0.91 & 0.70 & 0.95 & 0.94 & & 0.0150 & -0.008 & 0.033 \\
\hline Mackenzie & Arctic Red & 2.26 & 3.90 & & -0.21 & -3.10 & & 0.88 & 0.60 & 0.95 & 0.93 & & -0.008 & & 0.293 \\
\hline
\end{tabular}

improved model simulation was demonstrated using NASH to test the bias in modeled $T_{w}$, with all stations having values greater than 0.85 , which exceeded the previous values (Table 1), indicating very good simulations. On the other hand, the simulated summer maximum $T_{w}$ for the Arctic Red station of the Mackenzie River was slightly higher than observations (Fig. 2a). This station collected relatively few observations around the summer peaks, which may be one cause of the overestimation.

\section{b. Differences in seasonal air and water temperature}

River water has a high heat capacity, which can result in large deviations between surface water and air temperature, particularly when the water is frozen. The input of lateral heat from upstream and/or tributaries may further increase or conversely decrease the deviation between $T_{w}$ and $T_{a}$ (van Beek et al. 2012). The deviation was zonally averaged at individual latitudes with a $0.5^{\circ}$ resolution to analyze the meridional features. Figure 3 displays zonally averaged time-latitude cross sections for $T_{a}$ (Fig. 3a) and $T_{w}$ (Fig. $3 \mathrm{~b}$ ), and the deviation between them (Fig. 3c). It can be seen that $T_{w}$ had a similar seasonal variability to $T_{a}$, being warmer in the summer and colder in the winter. As expected, a large deviation was found in the winter months when the atmosphere was colder than the river, at $T_{w}=0^{\circ} \mathrm{C}$. From spring onward, the river remained colder than the atmosphere due to the high heat capacity of water. This cold deviation showed its maximum in July, ranging from $-4.5^{\circ}$ to $-0.5^{\circ} \mathrm{C}$ at the time-latitude cross section (Fig. 3c).

The monthly deviations between $T_{a}$ and $T_{w}$ exhibited region-specific features. In winter, the deviation was largest at $>70^{\circ} \mathrm{N}$ (Fig. 3c), where the coldest $T_{a}$ was found (Fig. 3a). The discharge of the Arctic river basins flows down from the southern headwaters, where $T_{a}$ is higher and streamflow is relatively low. Therefore, the upstream $T_{w}$ is warmer, and the deviation between the river surface and atmosphere is small. However, the $T_{w}$ in summer (June-August) at $53^{\circ}-60^{\circ} \mathrm{N}$ was higher than in the southern latitudes (Fig. 3b) and displayed a larger cold deviation (Fig. 3c). The southern headwaters of the Arctic river basins are characterized by high altitudes, and the mountainous climate likely leads to colder $T_{w}$. In reality, average summer WATCH $T_{a}$ produced lower values at some southern boundary regions of the Kara, Laptev, and Beaufort Basins than the more northern latitudes (Fig. S1a in the supplemental material). The volume of summer flow in streams at $<60^{\circ} \mathrm{N}$ was substantially lower than in the northern streams (Fig. S1b). The low-flow condition benefits heat exchange with the warmer atmosphere (Edinger et al. 1968). On the other hand, approximately nine large reservoirs (Peters and Prowse 2001; Yang et al. 2004a,b) are situated in the Arctic rivers within the region of $50^{\circ}-60^{\circ} \mathrm{N}$. Reservoir regulation generally decreases summer discharge at local (Peters and Prowse 2001) and basin (Adam and Lettenmaier 2008) scales, affecting $T_{w}$ in the summer. Liu et al. (2005) reported that reservoir control in the Vilui River of the Lena basin had a significant influence on $T_{w}$ at $350 \mathrm{~km}$ downstream of the dam, although it was insignificant at the river mouth. A modeling study also identified large influences of anthropogenic regulation on $T_{w}$ in summer, especially in small rivers (van Vliet et al. 2012). The CHANGE framework did not incorporate the effects of the reservoir on $T_{w}$ and $Q$, which probably suggests underestimations of the simulated $T_{w}$ at local and basin scales.

The monthly deviation between $T_{a}$ and $T_{w}$ at the time-latitude cross section reveals the impact of lateral 
(a) zonal mean surface air temperature, Ta

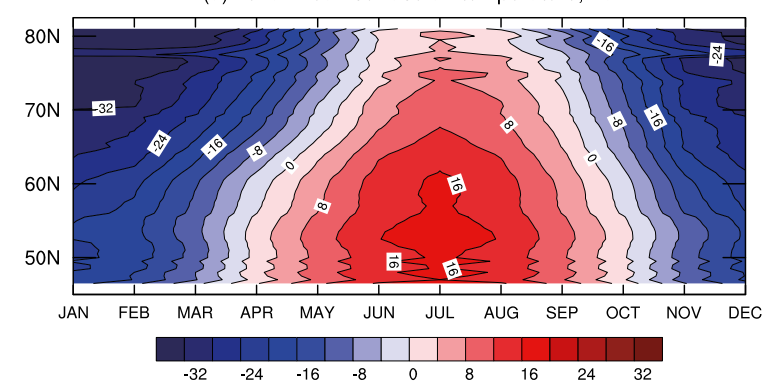

(b) zonal mean water temperature, Tw

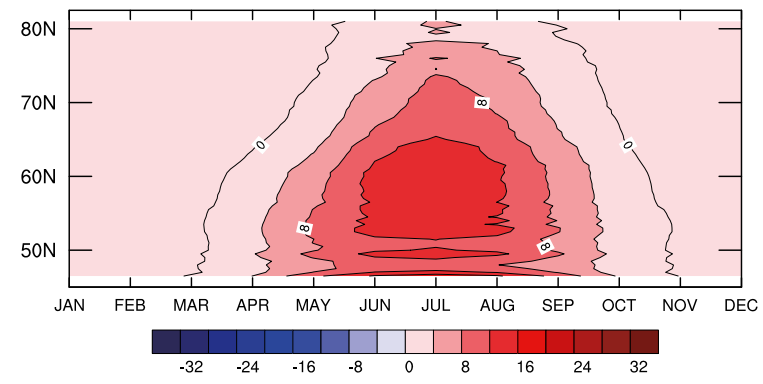

(c) zonal mean deviation, Tw-Ta

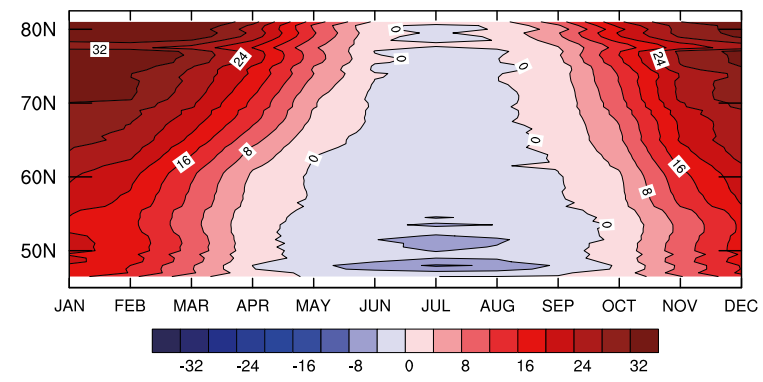

FIG. 3. Time-latitude graphs of zonal mean (a) monthly air temperature, (b) river water temperature, and (c) the deviation between air temperature and river water temperature, which were each averaged over the 1979-2013 period.

heat transport through the river network (Fig. 3). At northern latitudes, the hydroclimatology of a colder climate and higher discharge (Fig. S1) can reduce the warming rate of rivers. However, there were no large differences in the summer deviation at latitudes $>60^{\circ} \mathrm{N}$, probably due to the influence of relatively warm water flowing in from the southern upper rivers. The impact of lateral heat transport persisted until late summer, maintaining smaller differences between the latitudes.

\section{c. Trends in river water temperature}

The simulated daily $T_{w}$ at all basin mouths (Fig. 1) was averaged by the flow volume weighting of individual river basins over an annual scale. Figure 4 displays the time series of annual anomalies in $T_{w}$, as well as the integrated $Q$ and averaged $T_{a}$ for the same period. Water temperature measured at the river mouths carries

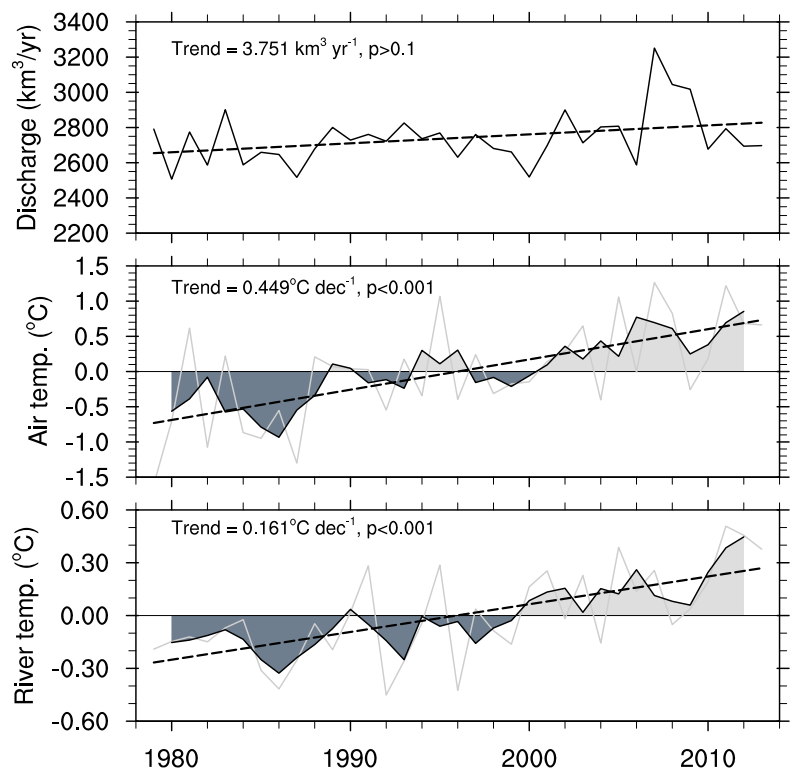

FIG. 4. Internal variability and trend (dashed lines) in (top) annual total discharge, (middle) annual air temperature anomaly averaged over the pan-Arctic mainland, and (bottom) annual average river temperature at the outlets of Arctic rivers. In the middle and bottom, the dark lines represent 3-yr running means of the annual anomalies (light gray lines) of the variables.

the aggregated influences on the river thermal regime of the topography, meteorology, and hydrology within the basin. Therefore, $T_{a}$ was averaged for the entire grid of the Arctic rivers. Parameter $T_{w}$ increased $\left(0.16^{\circ} \mathrm{C} \mathrm{decade}^{-1}\right.$, $p<0.001)$, as did $T_{a}\left(0.45^{\circ} \mathrm{C}\right.$ decade $\left.^{-1}, p<0.001\right)$, over the period of 1979-2013. Relatively stronger increases in $T_{w}$ were apparent after 2000 when the warming in WATCH $T_{a}$ data was very large. Annual $T_{w}$ anomalies showed interannual variations similar to $T_{a}$ over the study period $(r=0.69, p<0.001)$, while the correlation between $T_{w}$ and $Q$ was lower $(r=0.20, p>0.1)$. These correlation statistics indicate the major influence of $T_{a}$ on the interannual variations of $T_{w}$. The lower correlation between $T_{w}$ and $Q$ does not mean that the influence of $Q$ on $T_{w}$ was trivial. The increase in $Q$ has the reverse impact on $T_{w}$ because of the high heat capacity of water, reducing the relative contribution of $T_{a}$ to $T_{w}$.

The trends in annual mean $T_{w}$, annual mean $T_{a}$, and total $Q$, in the Arctic sea drainage regions (Fig. 1) are compared in Table 2. Statistically significant increases of $T_{w}(p<0.01)$ were found in Eurasian basins (i.e., Barents, Kara, Laptev, and East Siberia), which was consistent with the significant warming of $T_{a}(p<0.02)$. Parameter $Q$ also increased in all of the Eurasian basins, except for the Barents. The increase in $Q$ was significant in early spring (Fig. 5c) (Holmes et al. 2015) when $T_{a}$ 
TABLE 2. Trend values of annual mean water temperature and air temperature and annual discharge in each river sea basin defined in Fig. 1 during the study period of 1979-2013. The annual mean water temperature was averaged by the flow volume weighting of rivers within individual sea basins. Variable $p$ represents the probability value of the trend.

\begin{tabular}{|c|c|c|c|c|c|c|}
\hline \multirow[b]{2}{*}{ Sea basin } & \multicolumn{2}{|c|}{ Water temperature } & \multicolumn{2}{|c|}{ Air temperature } & \multicolumn{2}{|l|}{ Discharge } \\
\hline & Trend $\left({ }^{\circ} \mathrm{C}\right.$ decade $\left.{ }^{-1}\right)$ & $p$ & Trend $\left({ }^{\circ} \mathrm{C}\right.$ decade $\left.{ }^{-1}\right)$ & $p$ & Trend $\left(\mathrm{km}^{3}\right.$ decade $\left.^{-1}\right)$ & $p$ \\
\hline Barents & 0.22 & $<0.005$ & 0.49 & $<0.004$ & -0.33 & $>0.100$ \\
\hline Kara & 0.16 & $<0.005$ & 0.40 & $<0.020$ & 13.47 & $>0.100$ \\
\hline Laptev & 0.20 & $<0.001$ & 0.48 & $<0.002$ & 17.92 & $<0.050$ \\
\hline East Siberia & 0.15 & $<0.003$ & 0.48 & $<0.001$ & 8.17 & $<0.050$ \\
\hline Chukchi & 0.04 & $>0.100$ & 0.29 & $<0.050$ & 2.45 & $>0.100$ \\
\hline Beaufort & -0.01 & $>0.100$ & 0.33 & $<0.030$ & 1.35 & $>0.100$ \\
\hline Archipelago & 0.06 & $>0.100$ & 0.74 & $<0.001$ & 5.92 & $>0.100$ \\
\hline
\end{tabular}

remains around the freezing point, thereby lowering the negative impact of $Q$ on $T_{w}$. This study estimated positive trends $\left(\sim 0.15^{\circ}-0.22^{\circ} \mathrm{C}\right.$ decade $\left.^{-1}\right)$ for $T_{w}$ of the four Eurasian basins, which were comparable to the $T_{w}$ trends ranging from $-0.31^{\circ}$ to $+0.22^{\circ} \mathrm{C}$ decade ${ }^{-1}$ derived from observations made during 1929-2003 at 20 river mouths located within the Eurasian basins (Lammers et al. 2007) (Table 1). Although the comparisons include differences in the data period and regions/basins in the analysis, the trends in $T_{w}$ estimated by this study strongly suggest a link with the warming $T_{a}$ diagnosed during the recent decade. The trends of $T_{w}$ in the North American basins, including the Chukchi basin, were low relative to the Eurasian basins. However, unexpected $T_{w}$ cooling $\left(-0.01^{\circ} \mathrm{C}\right.$ decade $\left.^{-1}, p>0.1\right)$ was found in the Beaufort Basin (Table 2), which deviated from the $T_{a}$ warming $\left(0.33^{\circ} \mathrm{C}\right.$ decade $\left.^{-1}, p<0.03\right)$. To explain this, we analyzed the $T_{a}$ at seasonal scales. Intermittently larger negative WATCH $T_{a}$ anomalies appeared in spring and summer during 1999-2010 over the Beaufort Basin (Fig. S2). Considering the strong sensitivity of $T_{w}$ to $T_{a}$ (Yang and Peterson 2017), it is possible that the spring and summer $T_{a}$ anomalies likely account for some portion of the negative $T_{w}$ trend.

Monthly average $T_{w}$ at the mouths of the Arctic rivers show increases during the warm season (Fig. 5a), consistent with increases in the WATCH $T_{a}$ for the Arctic regions (Fig. 5b). Increases in $T_{a}$ were especially significant in the early spring and late autumn. The greatest increase in Arctic river $Q$ was found in May (Fig. 5c), probably due to earlier snowmelt in surrounding land areas (Park et al. 2016). Interestingly, a greater increase in $T_{w}$ was predicted in June $\left(0.52^{\circ} \mathrm{C} \mathrm{decade}^{-1}, p<0.001\right)$. In Arctic rivers, the peak $Q$ is generally observed in June. The large heat capacity associated with high river flow may inhibit the typical $T_{w}$ increase in June. However, Arctic river $Q$ showed a decreasing trend in June $\left(-3.03 \mathrm{~km}^{3} \mathrm{yr}^{-1}, p>0.1\right.$; Fig. $\left.5 \mathrm{c}\right)$ as a result of the earlier shift of hydrograph (Holmes et al. 2015). In addition to the decrease in $Q$, the increase in $T_{a}$ contributes to large increases in $T_{w}$ in June, increasing heat exchange at the river surface. The outflow of water heated in the upper rivers also contributed to the increase in downstream $T_{w}$. Warmer $T_{a}$ in early spring can result in early river-ice breakup, contributing to warmer $T_{w}$. Data analysis and model results both indicated widespread early ice breakup in the pan-Arctic rivers (Park et al. 2016).

Figure 6 shows the spatial distributions of the trends in modeled annual $T_{w}$ and annual WATCH $T_{a}$ during the period of 1979-2013. There were widespread increases in $T_{w}$ in the Arctic rivers (Fig. 6a), which was similar to the trends in $T_{a}$ (Fig. 6b). Relatively large increases were apparent on the Eurasian continent, particularly in northeastern Europe $(p<0.1)$. A significant decrease in $T_{w}$ occurred in the upper reaches of the Mackenzie basin, and sporadically in the southern upper reaches of the $\mathrm{Ob}$ and Yenisey basins, where $T_{a}$ exhibited decreasing or insignificant trends (Fig. 6b). This cohesive spatial pattern suggests that $T_{w}$ is very sensitive to variations and changes in $T_{a}$ (Yang and Peterson 2017). On the other hand, there have been significant decreases in winter snowfall over the Mackenzie River basin since 1990 (Park et al. 2013), at a time when $T_{a}$ in the spring and summer displayed negative anomalies (Fig. S2). The resultant low $Q$ (Yang et al. 2015) reduces the heatstorage-related negative effect on $T_{w}$, increasing the sensitivity of $T_{w}$ to atmospheric warming and cooling (Edinger et al. 1968). Parameter $T_{w}$ is therefore impacted by the cold $T_{a}$ anomalies in the spring and summer.

\section{d. Model sensitivity experiments}

Experiments were conducted to examine the sensitivity of modeled $T_{w}$ to $T_{a}$ and $Q$. Figure 7 displays the average differences between the sensitivity experiments and the control simulation at the outlets of the panArctic rivers (Fig. 1) for the period of 1979-2013. The 

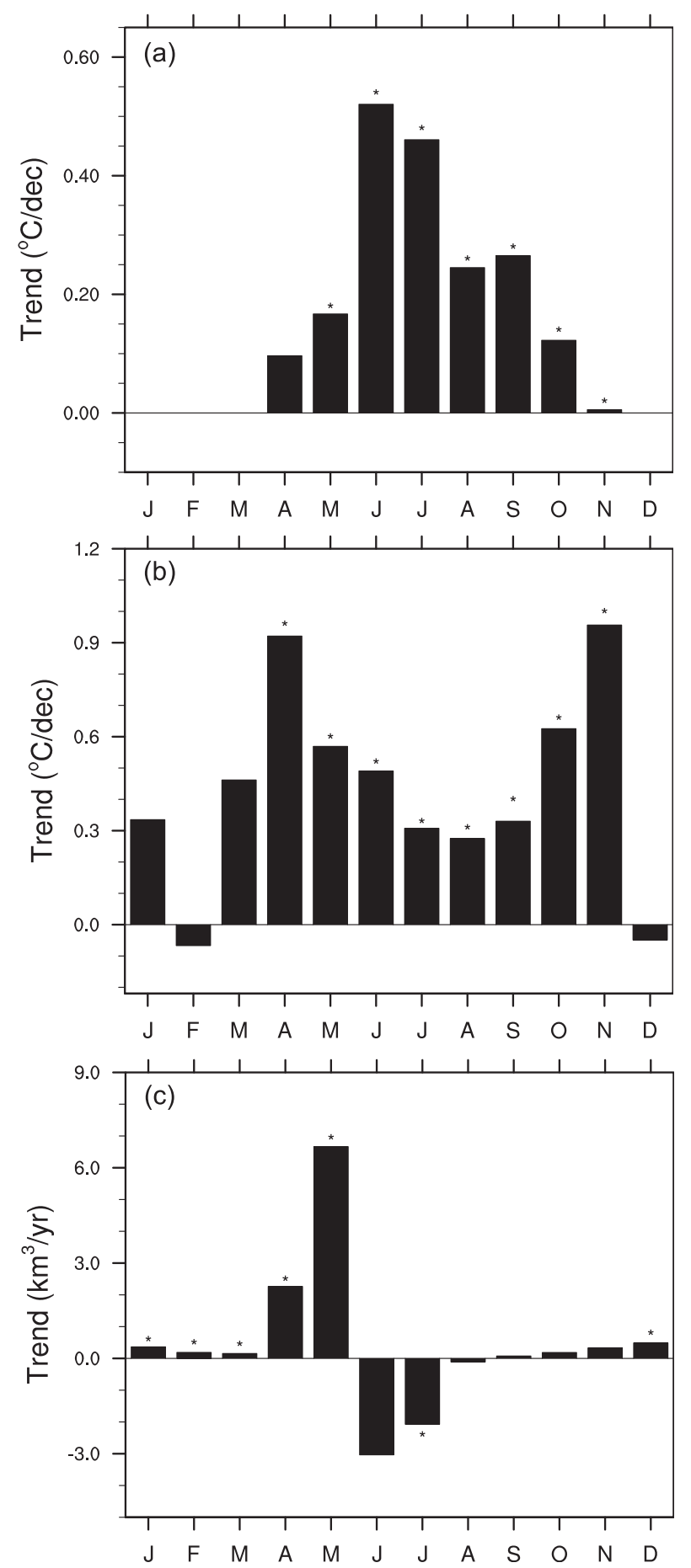

FIG. 5. Monthly trends in (a) river water temperature, (b) air temperature, and (c) discharge during the 1979-2013 simulation period. Individual variables represent values calculated for the same regions and stations as described in Fig. 4. Statistically significant trends $(p<0.1)$ are marked by asterisks. model-estimated $T_{w}$ was sensitive to changes in $T_{a}$, with an increase in $T_{a}$ corresponding to an increase in $T_{w}$, and they similarly decreased together. The absolute changes in $T_{w}$ were slightly larger when $T_{a}$ decreased and smaller when $T_{a}$ increased. However, the change in $T_{w}$ was not linear relative to $T_{a}$. For example, $T_{w}$ decreased by $0.41^{\circ} \mathrm{C}$ at the outlets of the Arctic rivers in response to a $-2^{\circ} \mathrm{C}$ change in $T_{a}$ and increased $+0.48^{\circ} \mathrm{C}$ with a $+2^{\circ} \mathrm{C}$ change in $T_{a}$ (Fig. 7). Simulations using a nonlinear $T_{w}$ regression model produced increases of $0.6^{\circ}-1.3^{\circ} \mathrm{C}$ in $T_{w}$ with a $+2^{\circ} \mathrm{C}$ change in $T_{a}$ at the downstream stations of Russian rivers (i.e., Ob, Yenisey, and Lena; van Vliet et al. 2011). At high latitudes, river flow in early summer was characterized by a higher water depth, with a larger heat capacity, which inhibited the warming of rivers (Yang et al. 2005; Lammers et al. 2007). Thus, changes in $T_{a}$ were not expressed linearly as changes in $T_{w}$ (van Vliet et al. 2011).

Results of the sensitivity experiments indicated an inverse relationship between $Q$ and $T_{w}$. An increase of $+50 \%$ in $Q$ resulted in a decrease of $0.20^{\circ} \mathrm{C}$ in $T_{w}$, while decreases in $Q$ promoted moderate $T_{w}$ increases (Fig. 7). A process-based model estimated a change of $-0.1^{\circ} \mathrm{C}$ in $T_{w}$ given a $+50 \%$ change in $Q$ over river basins globally (van Vliet et al. 2012). The sensitivity of $T_{w}$ to changes in $Q$ was not as great as the sensitivity to $T_{a}$. This difference may be associated with the heat capacity of river water (van Vliet et al. 2012). The influence of $Q$ on $T_{w}$ may be promoted or reduced when combined with changes in $T_{a}$. The combination of $+2^{\circ} \mathrm{C}$ in $T_{a}$ and $+25 \%$ in $Q$ led to a $T_{w} 0.02^{\circ} \mathrm{C}$ lower than $+2^{\circ} \mathrm{C}$ $T_{a}$, without discharge changes (Fig. 7). These experimental results indicate that $T_{w}$ in the Arctic rivers was more sensitive to changes in $T_{a}$ than in $Q$ (Yang and Peterson 2017).

\section{Discussion}

This study improved the river $T_{w}$ model (Park et al. 2016) by inclusion of river surface energy exchanges and heat transfer from the upstream river network. The model was applied to all Arctic rivers (Fig. 1) on a daily basis over long periods without calibration. Comparison with observations taken at or near the outlet stations of the major Arctic rivers indicated a good model performance for simulating seasonal and interannual variations in $T_{w}$ (Fig. 2). The model increased the maximum summer $T_{w}$ by about $6^{\circ} \mathrm{C}$ (Fig. 2) relative to the values estimated by the previous version, which did not include heat advection (Park et al. 2016). The significant improvement in the model results was also demonstrated by statistical measures; that is, the NASH values were higher than 0.85 and RMSE was less than $2.6^{\circ} \mathrm{C}$ 

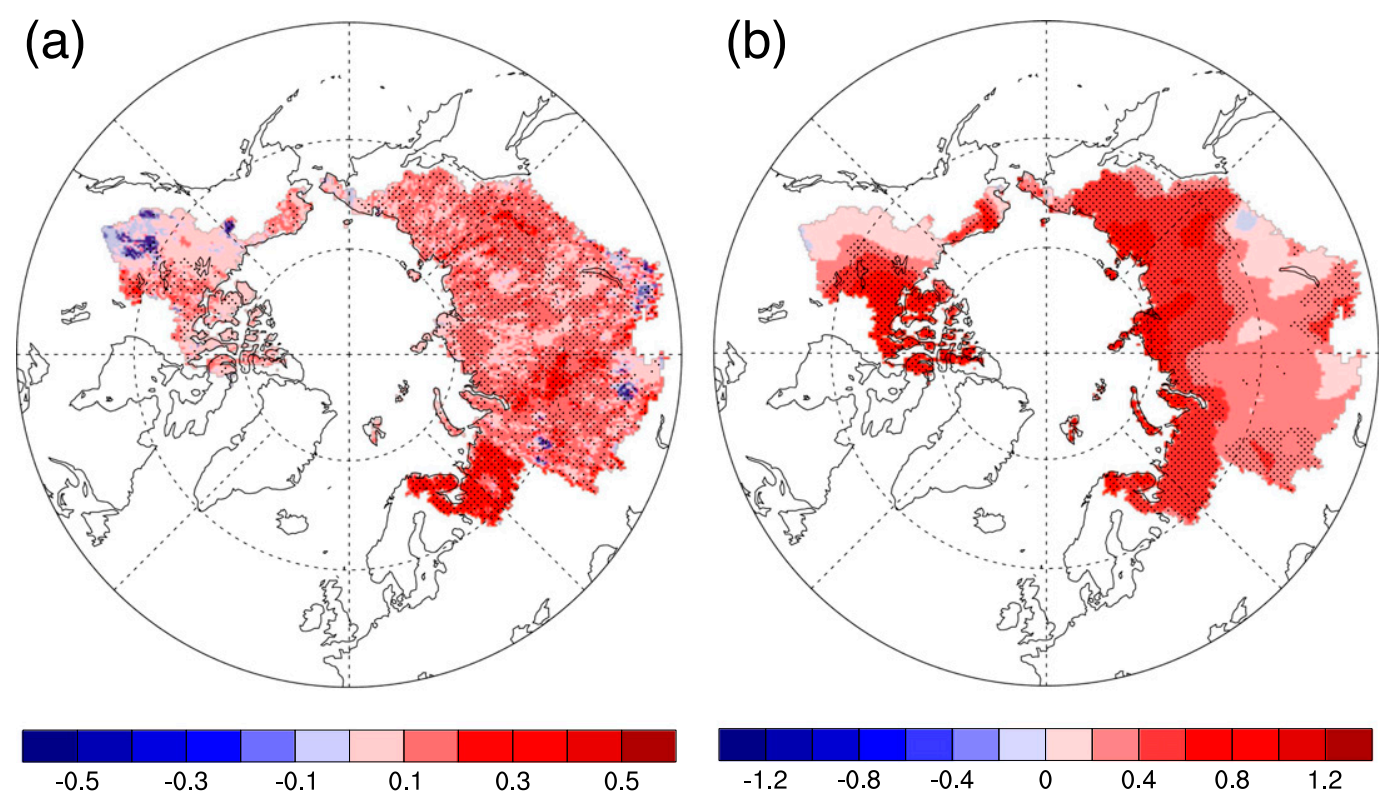

FIG. 6. Spatial trends in (a) modeled river temperature and (b) WATCH-based air temperature averaged over the period of 1979-2013. The dots represent statistically significant trends $(p<0.1)$, as diagnosed by the nonparametric Mann-Kendall test.

(Table 1). The bias $\left(<0.70^{\circ} \mathrm{C}\right)$ of model simulations in this study was comparable with the mean absolute errors of $1.6^{\circ}-7.6^{\circ} \mathrm{C}$ in daily simulations at the global scale (van Beek et al. 2012; van Vliet et al. 2012). These improved model simulations emphasize that heat advection through upper river systems is an important process affecting the $T_{w}$ of Arctic rivers. In Arctic rivers, water flows toward northern outlets from the southern latitudes. Although $T_{a}$ at the northern latitudes has exhibited significant increasing trends during recent decades (Bekryaev et al. 2010), the northern $T_{a}$ is generally lower than in the south. This low $T_{a}$ yields low $T_{w}$. However, the lateral transport of energy through the southern rivers can result in water that is warmer than the atmosphere in northern rivers. The influence of lateral heat transport on $T_{w}$ is apparent in the smaller temperature difference between the river surface and the atmosphere at northern latitudes (Fig. 3c).

Previous studies reported poor model results for $T_{w}$ in Arctic rivers, due to poor simulation of the start and end dates of ice cover. For example, one model simulated later ice breakup, causing $T_{w}$ to rise too late in the spring and thereby predicting colder $T_{w}$ in summer (van Beek et al. 2012). Compared with previous results (Park et al. 2016), this modeling framework considerably improves simulation of the seasonal variation in $T_{w}$, including the timing of ice breakup and formation (Fig. 2). In particular, the good model performance for spring $T_{w}$ can be attributed to improved calculation of snowmelt timing by the CHANGE model (Park et al. 2011). In the Arctic, snowmelt processes, such as the timing and melt rate of the snowpack, are directly related to the timing and amount of spring flow, including the peak discharge. Considering the influences of $Q$ on $T_{w}$ (Ficklin et al. 2012; van Vliet et al. 2011, 2012; van Beek et al. 2012), the deviation of simulated discharge from observations

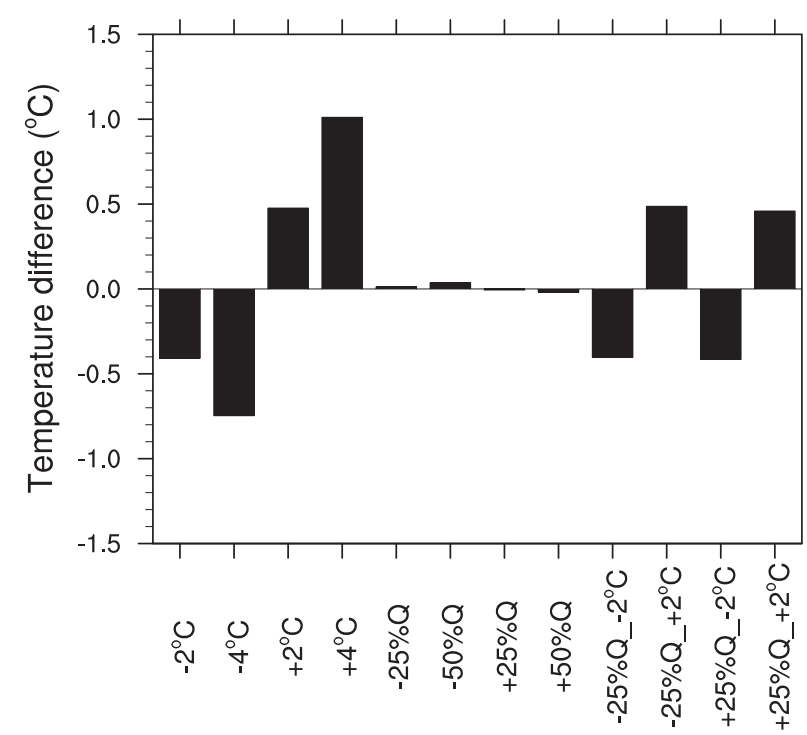

FIG. 7. Differences in river temperatures estimated in the individual model experiments from the unadjusted baseline for the outlets of the pan-Arctic rivers for the 1979-2013 simulation period. 
likely propagates to a biased estimation of $T_{w}$. However, this modeling framework captured the peak spring discharge at most stations in the major river basins across climate zones (Park et al. 2016). On the other hand, Arctic warming has resulted in greater and earlier peak discharge in the last decade (Shiklomanov et al. 2007; Holmes et al. 2015), corresponding to early spring melting of deeper snow (Lesack et al. 2014; Park et al. 2015; Yang et al. 2007). Moreover, the formation of river ice occurred later in autumn (Park et al. 2016). Despite these changes, the model presented here realistically simulated $T_{w}$ in the context of the present climate, increasing the model's applicability to study future $T_{w}$ dynamics under conditions of climate change and increasing anthropogenic activity.

This study shows that, because of warming of the Arctic climate, the mean $T_{w}$ has increased by $0.16^{\circ} \mathrm{C}$ decade $^{-1}(p<0.001)$ at the outlets of pan-Arctic rivers (Fig. 1), with similar warming in $T_{a}$ records (Fig. 4). To the best of our knowledge, this assessment is the first comprehensive, long-term modeling analysis of $T_{w}$ over the pan-Arctic rivers. In spatial terms, the trends in simulated $T_{w}$ exhibited large regional heterogeneity (Fig. 6); the $T_{w}$ increase was significant in Eurasian rivers, while $T_{w}$ in the Mackenzie River basin showed an insignificant negative trend, similar to $T_{a}$. These results emphasize the role of $T_{a}$ as the main factor affecting $T_{w}$ variation (Webb et al. 2008), as demonstrated by the model sensitivity experiments (Fig. 7). On the other hand, previous studies have documented a higher sensitivity of $T_{w}$ to $Q$ for rivers globally (van Vliet et al. 2011, 2012). Our analyses, including the model sensitivity experiments, indicated that the impact of $Q$ on $T_{w}$ was moderate relative to the effect of $T_{a}$ on an annual basis (Fig. 7). Relatively cold Arctic water travels a longer distance to the downstream outlets, for example, more than $4000 \mathrm{~km}$ in the case of the Lena River. River water volume increases as it flows toward the northern basin outlets. This results in a larger river heat capacity, which in turn leads to the cooling of river $T_{w}$. However, heat exchange occurs during this movement of water at the river surface due to lateral input of relatively warm water from the upper rivers. These heat fluxes reduce the impact of discharge on $T_{w}$. As a result, the influence of $Q$ on $T_{w}$ is not greater than that of $T_{a}$.

Very few studies of river $T_{w}$ at the pan-Arctic scale have been conducted, limiting the data available for comparison with model-derived $T_{w}$ trends, although one previous study (Lammers et al. 2007) reported basinscale trends in $T_{w}$ of Russian rivers based on long-term observations. We calculated trends in simulated $T_{w}$ in the same rivers (Table 1). The observational data indicated negative trends for some rivers (e.g., Ob,
Yenisey, and Indigirka), which was inconsistent with model results. Lammers et al. (2007) suggested that permafrost-derived meltwater and reservoir controls caused the negative trends. Increases in winter minimum flow have been observed in permafrost watersheds on the Eurasian continent (Smith et al. 2007). A modeling experiment has found nonnegligible contributions of groundwater advection and snow-water recharge to $T_{w}$ in smaller rivers of the western United States (Ficklin et al. 2012). Anthropogenic perturbations, such as dams and reservoirs that have not yet been incorporated in the CHANGE model, also had significant influences on $T_{w}$ and $Q$, especially in rivers at the local scale (Liu et al. 2005). The lack of those variables in this modeling framework has likely increased uncertainties in the $T_{w}$ simulations. With the rough spatial resolution of $0.5^{\circ}$, the treatment of fixed values for channel width and shape in individual grid pixels can also introduce uncertainties into the $T_{w}$ simulations. Above all, an important reason for the differences in the trends was probably due to their different analysis periods. Lammers et al. (2007) did not include years after 2000, and $T_{a}$ significantly increased (Fig. 4) during their analysis. Considering the strong sensitivity of $T_{w}$ to $T_{a}$, the modeled $T_{w}$ warming trends may not deviate greatly from the present climate context. However, more detailed investigations comparing the $T_{w}$ simulations with in situ observations are required.

\section{Conclusions}

Water temperature has an important impact on many aspects of river hydrology and ecology and is relatively easy to measure. Parameter $T_{w}$ has been systematically measured in Russian operational and research networks, but observations of northern North American rivers lack the benefit of a systematic network. The Arctic climate has experienced significant changes in recent decades, but few assessments of changes in river $T_{w}$ at the pan-Arctic scale are available. This study employed a physically based process model with a detailed land process model (CHANGE) coupled to hydrological process models of river discharge, ice, and $T_{w}$ dynamics. The river $T_{w}$ model was improved by incorporating the processes of heat exchange at the air-water interface and heat transfer from the river upstream through the channel network.

The model framework was applied to all Arctic rivers, and then we quantitatively assessed $T_{w}$ changes and trends over the period of 1979-2013, in which $T_{a}$ warmed significantly. The simulated $T_{w}$ showed good agreement with observations at the mouths of the major Arctic rivers, highlighting the considerable improvement in simulation quality relative to the old framework 
(Park et al. 2016). The modeled $T_{w}$ indicated warming trends at the outlets of all Arctic rivers and at the panArctic spatial scale during the study period. The trend and variability in $T_{w}$ were significantly correlated with $T_{a}$ changes and variability. Meanwhile, river discharge played a role in offsetting the $T_{a}$ impact on $T_{w}$, due to the large heat capacity of water. These findings were verified by model sensitivity analysis based on various scenarios of $T_{a}$ and $Q$. Future climate warming is expected to further increase $T_{w}$, and it has been projected that river discharge will increase with future precipitation changes. A larger $Q$ can reduce the impact of $T_{a}$ on $T_{w}$, likely resulting in $T_{w}$ changes diverging from the warming trend of $T_{a}$. From that perspective, the physical process-based model is useful for investigating $T_{w}$ changes under climate change scenarios.

The Arctic rivers provide freshwater to the Arctic Ocean, which carries with it a heat supply that impacts seasonal sea ice retreat and the warming of sea shelf waters (Janout et al. 2016). A considerable area of the shelf is underlain by submerged permafrost, and thermal variability in the shelf has the potential to impact this permafrost. The $T_{w}$ assessments of Arctic rivers may provide the necessary information to understand and quantify changes that have occurred on the Arctic coastal area in recent decades and will continue in the future.

Acknowledgments. This work was supported in part by the Japan Agency for Marine-Earth Science and Technology (JAMSTEC) and the Ministry of Education, Culture, Sports, Science and Technology, Grant-inAid for Scientists (C) 26340018 and for Young Scientists (B) 26870023 . We would also like to thank three anonymous reviewers who provided very detailed comments on all aspects of this paper.

\section{REFERENCES}

Adam, J. C., and D. P. Lettenmaier, 2008: Application of new precipitation and reconstructed streamflow products to streamflow trend attribution in northern Eurasia. J. Climate, 21, 1807-1828, doi:10.1175/2007JCLI1535.1.

Alkire, M. B., A. D. Jacobson, G. O. Lehn, and R. W. Macdonald, 2015: Small rivers could have big impact on Arctic Ocean. Eos, Trans. Amer. Geophys. Union, 96, doi:10.1029/2015EO034005.

Bekryaev, R. V., I. V. Polyakov, and V. A. Alexeev, 2010: Role of polar amplification in long-term surface air temperature variations and modern Arctic warming. J. Climate, 23, 3888-3906, doi:10.1175/2010JCLI3297.1.

Caissie, D., 2006: The thermal regime of rivers: A review. Freshwater Biol., 51, 1389-1406, doi:10.1111/j.1365-2427.2006.01597.x.

, M. G. Satish, and N. El-Jabi, 2007: Predicting water temperature using a deterministic model: Application on Miramichi River catchments (New Brunswick, Canada). J. Hydrol., 336, 303-315, doi:10.1016/j.jhydrol.2007.01.008.
Edinger, J. E., D. W. Duttweiler, and J. G. Geyer, 1968: Response of water temperatures to meteorological conditions. Water Resour. Res., 4, 1137-1143, doi:10.1029/WR004i005p01137.

Ficklin, D. L., Y. Luo, I. T. Stewart, and E. P. Maurer, 2012: Development and application of a hydroclimatological stream temperature model within the Soil and Water Assessment Tool. Water Resour. Res., 48, W01511, doi:10.1029/ 2011WR011256.

Holmes, R. M., A. I. Shiklomanov, S. E. Tank, J. W. McClelland, and M. Tretiakov, 2015: River discharge. Arctic Report Card 2015, M. O. Jeffries, J. Richter-Menge, and J. E. Overland, Eds., NOAA Tech. Doc., 60-65. [Available online at ftp:// ftp.oar.noaa.gov/arctic/documents/ArcticReportCard_full_ report2015.pdf.]

Janout, M., and Coauthors, 2016: Episodic warming of near-bottom waters under the Arctic sea ice on the central Laptev Sea shelf. Geophys. Res. Lett., 43, 264-272, doi:10.1002/2015GL066565.

Lammers, R. B., J. W. Pundsack, and A. I. Shiklomanov, 2007: Variability in river temperature, discharge, and energy flux from the Russian pan-Arctic landmass. J. Geophys. Res., 112, G04S59, doi:10.1029/2006JG000370.

Lesack, L. F. W., P. Marsh, F. E. Hicks, and D. L. Forbes, 2014: Local spring warming drives earlier river-ice breakup in a large Arctic delta. Geophys. Res. Lett., 41, 1560-1566, doi:10.1002/2013GL058761.

Liu, B., D. Yang, B. Ye, and S. Berezovskaya, 2005: Long-term open-water season stream temperature variations and changes over Lena River basin in Siberia. Global Planet. Change, $\mathbf{4 8}$ 96-111, doi:10.1016/j.gloplacha.2004.12.007.

Ngo-Duc, T., T. Oki, and S. Kanae, 2007: A variable streamflow velocity method for global river routing model: Model description and preliminary results. Hydrol. Earth Syst. Sci. Discuss., 4, 4389-4414, doi:10.5194/hessd-4-4389-2007.

Oki, T., and Y. C. Sud, 1998: Design of Total Runoff Integrating Pathways (TRIP) - A global river channel network. Earth Interact., 2, doi:10.1175/1087-3562(1998)002<0001: DOTRIP $>2.3 . \mathrm{CO} ; 2$.

Overland, J., E. Hanna, I. Hanssen-Bauer, S.-J. Kim, J. E. Walsh, M. Wang, U. S. Bhatt, and R. L. Thoman, 2015: Surface air temperature. Arctic Report Card 2015, M. O. Jeffries, J. Richter-Menge, and J. E. Overland, Eds., NOAA Tech. Doc., 10-16. [Available online at ftp://ftp.oar.noaa.gov/arctic/ documents/ArcticReportCard_full_report2015.pdf.]

Park, H., Y. Iijima, H. Yabuki, T. Ohta, J. Walsh, Y. Kodama, and T. Ohata, 2011: The application of a coupled hydrological and biogeochemical model (CHANGE) for modeling of energy, water, and $\mathrm{CO}_{2}$ exchanges over a larch forest in eastern Siberia. J. Geophys. Res., 116, D15102, doi:10.1029/ 2010JD015386.

, J. Walsh, A. N. Fedorov, A. B. Sherstiukov, Y. Iijima, and T. Ohata, 2013: The influence of climate and hydrological variables on opposite anomaly in active-layer thickness between Eurasian and North American watersheds. Cryosphere, 7, 631-645, doi:10.5194/tc-7-631-2013.

_ A. N. Fedorov, M. N. Zheleznyak, P. Y. Konstantinov, and J. E. Walsh, 2015: Effect of snow cover on pan-Arctic permafrost thermal regimes. Climate Dyn., 44, 2873-2895, doi:10.1007/s00382-014-2356-5.

—_, Y. Yoshikawa, K. Oshima, Y. Kim, T. Ngo-Duc, J. S. Kimbal, and D. Yang, 2016: Quantification of warming climateinduced changes in terrestrial Arctic river ice thickness and phenology. J. Climate, 29, 1733-1754, doi:10.1175/ JCLI-D-15-0569.1. 
Peters, D. L., and T. D. Prowse, 2001: Regulation effects on the lower Peace River, Canada. Hydrol. Processes, 15, 3181-3194, doi:10.1002/hyp.321.

Peterson, B. J., R. M. Holmes, J. W. McClelland, C. J. Vorosmarty, R. B. Lammers, A. I. Shiklomanov, I. A. Shiklomanov, and S. Rahmstorf, 2002: Increasing river discharge to the Arctic Ocean. Science, 298, 2171-2173, doi:10.1126/science.1077445.

Prowse, T., A. Bring, J. Mård, E. Carmack, M. Holland, A. Instanes, T. Vihma, and F. J. Wrona, 2015: Arctic Freshwater Synthesis: Summary of key emerging issues. J. Geophys. Res. Biogeosci., 120, 1887-1893, doi:10.1002/2015JG003128.

Serreze, M. C., and Coauthors, 2006: The large-scale freshwater cycle of the Arctic. J. Geophys. Res., 111, C11010, doi:10.1029/ 2005JC003424.

Shiklomanov, A. I., R. B. Lammers, L. Smith, T. Pavelsky, and M. Rawlins, 2007: Temporal and spatial variations in maximum discharge from a new river flow data set for the Eurasian pan-Arctic. J. Geophys. Res., 112, G04S53, doi:10.1029/ 2006JF000571.

Sinokrot, B. A., and H. G. Stefan, 1993: Stream temperature dynamics: Measurements and modeling. Water Resour. Res., 29, 2299-2312, doi:10.1029/93WR00540.

Smith, L. C., T. M. Pavelsky, G. M. MacDonald, A. I. Shiklomanov, and R. B. Lammers, 2007: Rising minimum daily flows in northern Eurasian rivers: A growing influence of groundwater in the high-latitude hydrologic cycle. J. Geophys. Res., 112 G04S47, doi:10.1029/2006JD007574.

Stefan, H. G., and E. B. Preud'homme, 1993: Stream temperature estimation from air temperature. J. Amer. Water Resour. Assoc., 29, 27-45, doi:10.1111/j.1752-1688.1993.tb01502.x.

van Beek, L. P. H., T. Eikelboom, M. T. H. van Vliet, and M. F. P. Bierkens, 2012: A physically based model of global freshwater surface temperature. Water Resour. Res., 48, W09530, doi:10.1029/2012WR011819.

van Vliet, M. T. H., F. Ludwig, J. J. G. Zwolsman, G. P. Weedon, and P. Kabat, 2011: Global river temperatures and sensitivity to atmospheric warming and changes in river flow. Water Resour. Res., 47, W02544, doi:10.1029/2010WR009198.

_, J. R. Yearsley, W. H. P. Franssen, F. Ludwig, I. Haddeland, D. P. Lettenmaier, and P. Kabat, 2012: Coupled daily streamflow and water temperature modelling in large river basins. Hydrol. Earth Syst. Sci., 16, 4303-4321, doi:10.5194/ hess-16-4303-2012.

Webb, B. W., D. M. Hannah, R. D. Moore, L. E. Brown, and F. Nobilis, 2008: Recent advances in stream and river temperature research. Hydrol. Processes, 22, 902-918, doi:10.1002/hyp.6994.

Weedon, G. P., G. Balsamo, N. Bellouin, S. Gomes, M. J. Best, and P. Viterbo, 2014: The WFDEI meteorological forcing data: WATCH Forcing Data methodology applied to ERA-Interim reanalysis data. Water Resour. Res., 50, 7505-7514, doi:10.1002/2014WR015638.

Whitefield, J., P. Winsor, J. McClelland, and D. Menemenlis, 2015: A new river discharge and river temperature climatology data set for the pan-Arctic region. Ocean Modell., 88, 1-15, doi:10.1016/j.ocemod.2014.12.012.

Wunderlich, W. O., and R. Gras, 1967: Heat and mass transfer between a water surface and the atmosphere. Water Resources Research Laboratory Rep. 14, Tennessee Valley Authority, $270 \mathrm{pp}$.

Yang, D., and A. Peterson, 2017: River water temperature in relation to local air temperature in Mackenzie and Yukon basins. Arctic, 70, 47-58, doi:10.14430/arctic4627.

- B. Ye, and D. L. Kane, 2004a: Streamflow changes over Siberian Yenisei River basin. J. Hydrol., 296, 59-80, doi:10.1016/j.jhydrol.2004.03.017.

, _ _ and A. Shiklomanov, 2004b: Discharge characteristics and changes over the $\mathrm{Ob}$ River watershed in Siberia. J. Hydrometeor., 5, 595-610, doi:10.1175/1525-7541(2004)005<0595: DCACOT $>2.0 . \mathrm{CO} ; 2$.

$\longrightarrow$, B. Liu, and B. Ye, 2005: Stream temperature changes over Lena River basin in Siberia. Geophys. Res. Lett., 32, L05401, doi:10.1029/2004GL021568.

—, Y. Zhao, R. Armstrong, D. Robinson, and M.-J. Brodzik, 2007: Streamflow response to seasonal snow cover mass changes over large Siberian watersheds. J. Geophys. Res., 112, F02S22, doi:10.1029/2006JF000518.

, P. Marsh, and S. Ge, 2014: Heat flux calculations for Mackenzie and Yukon Rivers. Polar Sci., 8, 232-241, doi:10.1016/j.polar.2014.05.001.

_ , X. Shi, and P. Marsh, 2015: Variability and extreme of Mackenzie River daily discharge during 1973-2011. Quat. Int., 380-381, 159-168, doi:10.1016/j.quaint.2014.09.023. 